\title{
Experimental Consideration of Multistage Martensitic Transformation and Precipitation Behavior in Aged Ni-Rich Ti-Ni Shape Memory Alloys
}

\author{
Minoru Nishida ${ }^{1}$, Toru Hara ${ }^{2}$, Takuya Ohba $^{3}$, Koichi Yamaguchi ${ }^{1, *}$, \\ Koichi Tanaka ${ }^{1, *}$ and Kiyoshi Yamauchi ${ }^{4}$ \\ ${ }^{1}$ Department of Materials Science and Engineering, Kumamoto University, Kumamoto 860-8555, Japan \\ ${ }^{2}$ National Institute for Materials Science, Tukuba 305-0047, Japan \\ ${ }^{3}$ Department of Materials Science, Shimane University, Matsue 690-8504, Japan \\ ${ }^{4}$ NEC Tokin Corporation, Sendai 982-8510, Japan
}

It has been demonstrated with systematic experiments that the appearance and disappearance of multistage martensitic transformation in aged Ni-rich $\mathrm{Ti}-\mathrm{Ni}$ alloys depend on the heat treatment atmosphere. No multistage transformation occurs when the evaporation of $\mathrm{Ti}$ and $\mathrm{Ni}$ and/or the preferential oxidation of $\mathrm{Ti}$ in the specimen are prevented and the purification of heat treatment atmosphere in an evacuated quartz tube is achieved. The heterogeneity in precipitation morphology of $\mathrm{Ti}_{3} \mathrm{Ni}_{4}$ phase which is responsible for the multistage transformation can be suppressed with the regulation of heat treatment atmosphere as mentioned above. We have concluded that the multistage martensitic transformation in aged Ni-rich Ti-Ni alloys is an extrinsic nature, i.e., a kind of artifact during the heat treatment.

(Received August 21, 2003; Accepted October 22, 2003)

Keywords: Multistage martensitic transformation; $\mathrm{Ti}_{3} \mathrm{Ni}_{4}$ precipitate; Heat treatment atmosphere; Heterogeneous precipitation

\section{Introduction}

Ti-Ni alloys of the near-equiatomic composition are technologically important materials with their superior shape memory and superelastic properties associated with B2 to Rphase and B19' martensitic transformations. The application of the alloys has been spread to not only engineering but also medical and dental fields. It is widely recognized that improvements of shape memory and mechanical properties in the alloys are achieved by thermomechanical ${ }^{1)}$ and aging treatment. $^{2-4)}$ Especially, the aging treatment is an effective process in Ni-rich Ti-Ni alloys due to precipitation strengthening of the parent phase with coherent $\mathrm{Ti}_{3} \mathrm{Ni}_{4}$ phase. It has been known that the aging treatment induces the R-phase transformation. In addition to the generation of R-phase transformation, it has been also reported that the multistage martensitic transformation appears in the aged Ni-rich Ti-Ni alloys. $^{5-16)}$ Three mechanisms of multistage transformation have been proposed recently. ${ }^{12-14)}$ Bataillard et al. have ascribed it to coherent stress fields around $\mathrm{Ti}_{3} \mathrm{Ni}_{4}$ precipitates. ${ }^{12)}$ Khalil-Allafi et al. have explained it on the basis of evolving $\mathrm{Ni}$ concentration profiles between particles and differences in nucleation barriers between R-phase and B19' martensitic phase. ${ }^{13)}$ The latest report of Khalil-Allafi et al. has pointed out that the above two mechanisms cannot rationalize the multistage transformation, and thus the heterogeneity in precipitation morphology of $\mathrm{Ti}_{3} \mathrm{Ni}_{4}$ phase is responsible for the multistage transformation from TEM observations. ${ }^{14)}$ We do not intend to argue against those proposed mechanisms, because they have been discussed self-consistently within each experimental condition. However, some of the present authors have experienced that the multistage transformation is remarkably influenced by heattreatment conditions, especially heat-treatment atmosphere. ${ }^{16)}$ The homogeneity in precipitation morphology of

*Graduate Student, Kumamoto University
$\mathrm{Ti}_{3} \mathrm{Ni}_{4}$ phase has been also reported in several articles. $^{2,3,17-22)}$ We consider that the homogeneity in precipitation morphology is quite natural, since the atomic arrangement of $\mathrm{Ti}_{3} \mathrm{Ni}_{4}$ phase are a slight modification of the B2 type superstructure of matrix. ${ }^{19,20)}$ On the contrary, Filip and Mazanec have reported recently that aging of fully annealed, defect free materials results in heterogeneous grain boundary precipitation of $\mathrm{Ti}_{3} \mathrm{Ni}_{4}$ phase. ${ }^{23)}$ Khalil-Allafi et al. have reconfirmed the heterogeneous grain boundary precipitation. ${ }^{14)}$ They have also reported that the heterogeneous grain boundary precipitation is no longer observed when the aging is performed in the presence of external stresses as small as $2 \mathrm{MPa}$. Therefore, it is worth to reexamine the precipitation behavior of $\mathrm{Ti}_{3} \mathrm{Ni}_{4}$ phase in regard to the multistage martensitic transformation.

The purpose of the present study is to clarify experimentally whether the multistage martensitic transformation associated with the heterogeneity in precipitation morphology of $\mathrm{Ti}_{3} \mathrm{Ni}_{4}$ phase is an intrinsic nature or an extrinsic one in the aged Ni-rich Ti-Ni alloys.

\section{Experimental Procedure}

Ti-50.6 at $\% \mathrm{Ni}$ alloy was prepared from 99.7 mass $\%$ sponge $\mathrm{Ti}$ and 99.9 mass $\%$ electrolytic $\mathrm{Ni}$ by a highfrequency vacuum induction furnace using a graphite crucible, followed by casting into an iron mold. The ingot was hot-forged and cold-drawn to rod of $3 \mathrm{~mm}$ in diameter. The rod was cut into disks of about $1 \mathrm{~mm}$ in thickness for DSC measurements and about $0.2 \mathrm{~mm}$ in thickness for TEM observations, respectively. Half of the disks were solely sealed in an evacuated quartz tube of $2.5 \times 10^{-3} \mathrm{~Pa}$ as shown in Fig. 1(a), which is referred to as condition A hereinafter. The rest were sandwiched between Ti-Ni sheets of the same chemical composition. Subsequently, they were wrapped with pure Ti foil of $200 \mu \mathrm{m}$ in thickness and then sealed in an evacuated quartz tube of $2.5 \times 10^{-3} \mathrm{~Pa}$ as shown in Fig. 1(b), 
(a)

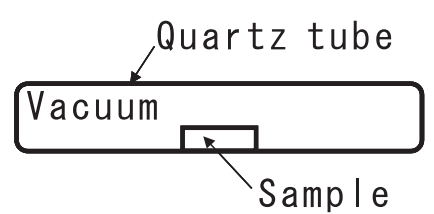

(b)

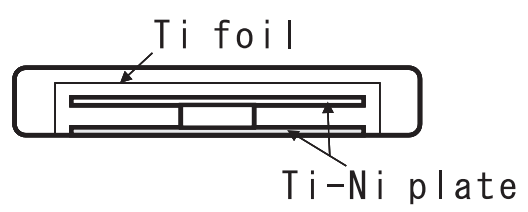

Fig. 1 Schematic illustration of heat treatment conditions (a) A and (b) B.

which is referred to as condition B hereinafter. They were solution-treated at $1273 \mathrm{~K}$ for $3.6 \mathrm{ks}$, and then quenched into ice water. Subsequently, the specimens were aged at $773 \mathrm{~K}$ for various periods, and then quenched into ice water. For instance, the specimen A-A described in the later section indicates that both the solution treatment and the aging are carried out in the condition A. In addition to conditions A and $\mathrm{B}$, conditions $\mathrm{C}$ to $\mathrm{G}$ described later were appended. The specimens obtained by various heat treatment conditions were lightly mechanically and chemically polished to remove the surface scale. DSC measurements were performed by using a Shimadzu DSC-50 calorimeter with cooling and heating rate of $10 \mathrm{~K} / \mathrm{min}$. TEM specimens were electropolished using the twin jet method in an electrolyte of $20 \%$ $\mathrm{H}_{2} \mathrm{SO}_{4}$ and $80 \% \mathrm{CH}_{3} \mathrm{OH}$ in volume around $270 \mathrm{~K}$. TEM observations were carried out in the JEOL-2000FX microscope operated at $200 \mathrm{kV}$.

\section{Results and Discussion}

\subsection{Effect of heat treatment atmosphere}

Figures 2(a) and (b) show DSC cooling curves of the solution treated specimens with the conditions A and B, respectively. There is no difference between the two DSC curves essentially. However, drastic change takes place in the

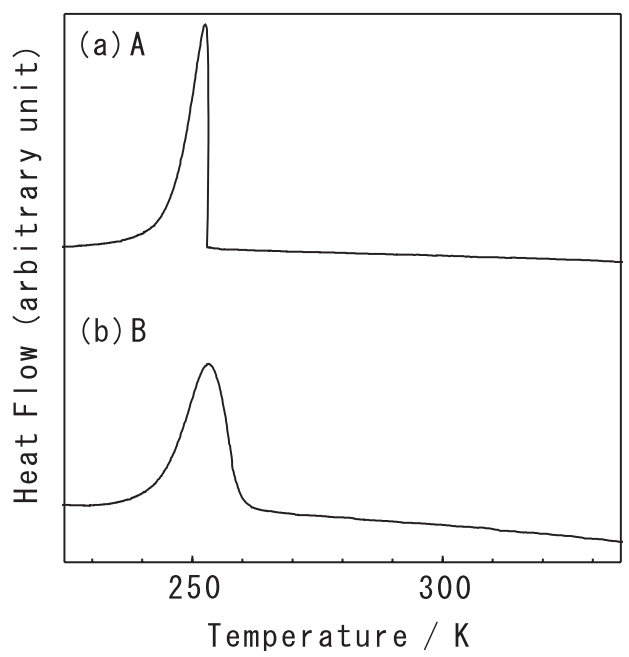

Fig. 2 DSC cooling curve of solution treated specimen with conditions (a) A and (b) B. (a) A-A

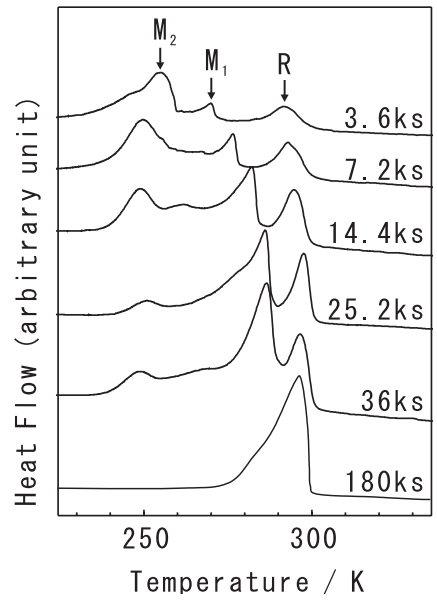

(b) $B-B$

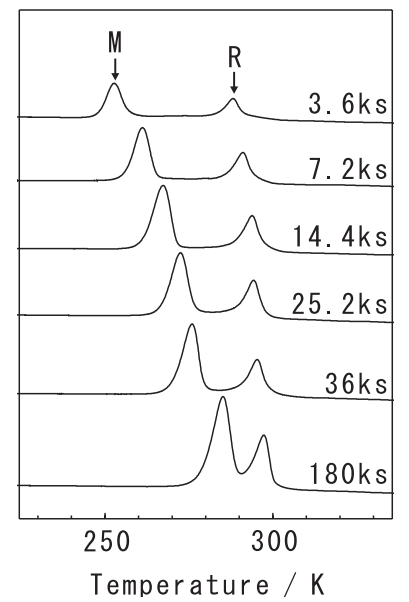

Fig. 3 DSC cooling curves of specimens (a) A-A and (b) B-B aged at $773 \mathrm{~K}$ for various periods.

aged specimen as follows. Figures 3(a) and (b) show DSC cooling curves of the specimens A-A and B-B aged at $773 \mathrm{~K}$ for various periods, respectively. The first peak denoted as $\mathrm{R}$, which corresponds to the B2 to R-phase transformation, can be seen in all the curves except for the specimen A-A aged for $180 \mathrm{ks}$. It is notable that the multistage martensitic transformation peaks denoted as $\mathbf{M}_{1}$ and $\mathrm{M}_{2}$ are clearly separated in the specimens A-A except for the specimen aged for $180 \mathrm{ks}$ as shown in (a). On the other hand, there are no multistage martensitic transformation peaks in all the DSC curves in the specimens B-B as seen in (b). The changes of DSC peak temperatures of the specimens A-A and B-B in Figs. 3(a) and (b) are summarized in Figs. 4(a) and (b), respectively, as a function of aging time in a linear logarithm plot. The $\mathrm{R}$ in both the specimens is almost constant from the early stage of aging and increases slightly with increasing aging time. The similar tendency has been previously reported in many articles. ${ }^{4,6,8,13,15,22)}$ Although the typical microstructures in A$\mathrm{A}$ and $\mathrm{B}-\mathrm{B}$ specimens are discussed later, the $\mathrm{R}$ is considered to be independent of microstructure changes such as size and dispersion density of $\mathrm{Ti}_{3} \mathrm{Ni}_{4}$ precipitates as reported so far. The $\mathrm{M}_{1}$ in A-A specimens linearly increases with increasing logarithm of aging time. It is mainly due to the decrease of $\mathrm{Ni}$ concentration in the transformation region. On the other hand, the $\mathrm{M}_{2}$ is constantly low up to aging time of $36 \mathrm{ks}$, besides the peak area indicated in Fig. 2(a) decreases, and then abruptly increases after prolonged aging period. The $\mathrm{M}$ in B-B specimen aged for $3.6 \mathrm{ks}$ slightly decreases, which is due to precipitation of coherent fine $\mathrm{Ti}_{3} \mathrm{Ni}_{4}$ particles. Such particles obstruct the shape change for the martensitic transformation. As increasing aging time the particles grow and the effect of Ni depletion in matrix becomes dominant, and thus the M linearly increases.

Subsequently, DSC measurement in specimens A-B and B-A aged at $773 \mathrm{~K}$ for $7.2 \mathrm{ks}$ is carried out to confirm a controlling factor in the multistage martensitic transformation. It is apparent that there is multistage martensitic transformation in the specimen A-B in Fig. 5(a), although the feature of DSC curve is quite different from that in the specimen A-A aged at $773 \mathrm{~K}$ for $7.2 \mathrm{ks}$ in Fig. 3(a). On the 

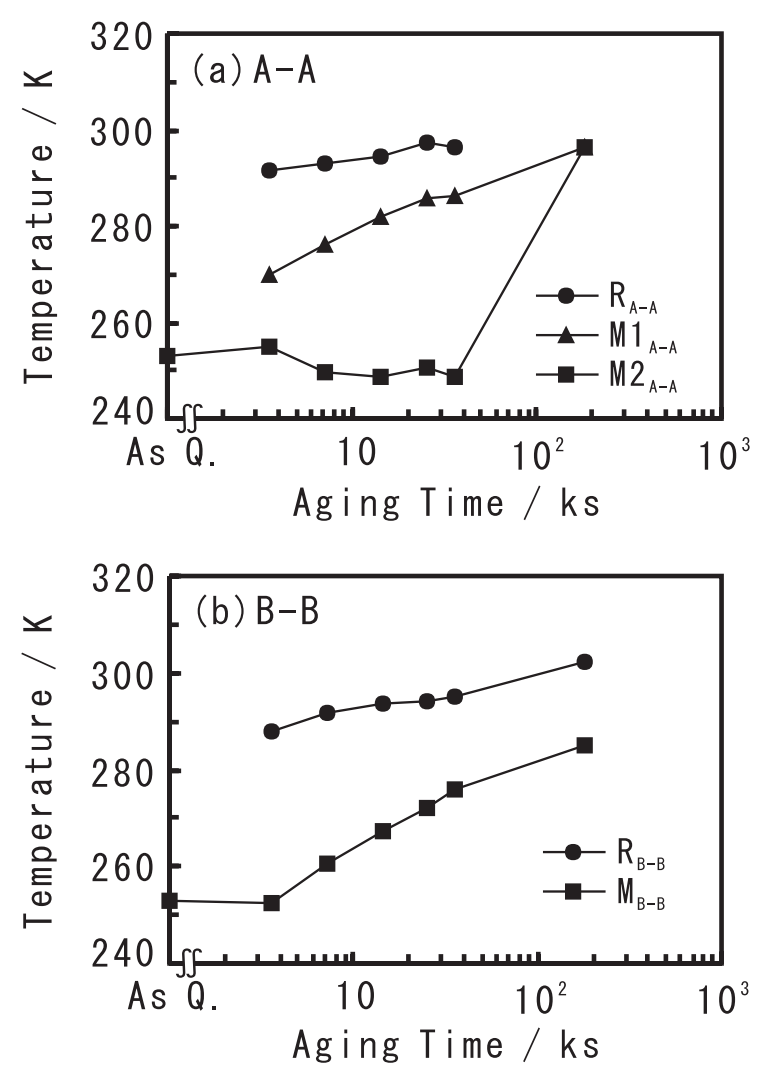

Fig. 4 DSC peak temperatures of specimens (a) A-A and (b) B-B aged at $773 \mathrm{~K}$ for various periods as function of aging time in linear logarithm plot.

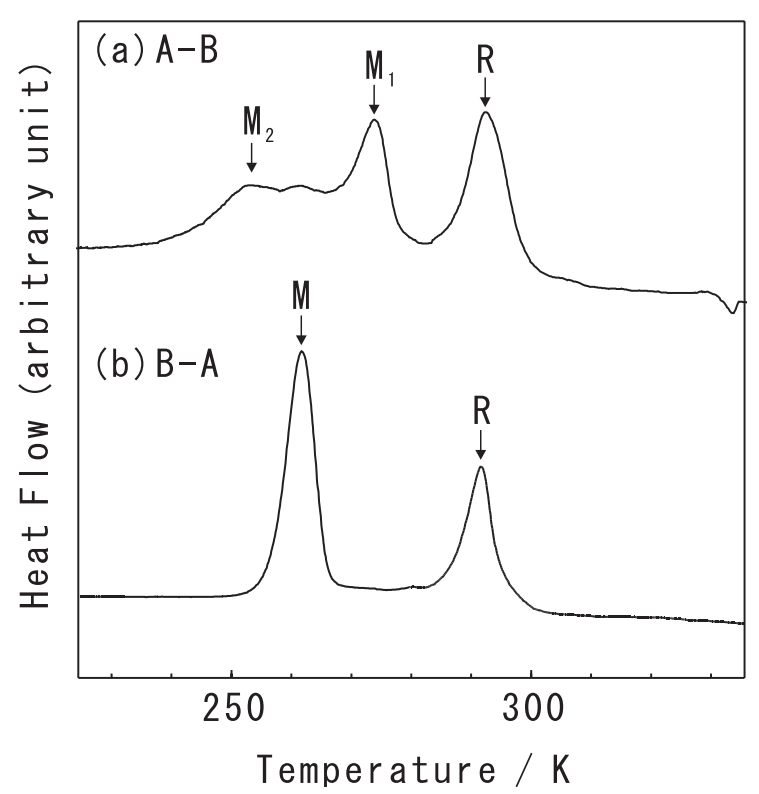

Fig. 5 DSC cooling curves of specimens (a) A-B and (b) B-A aged at $773 \mathrm{~K}$ for $7.2 \mathrm{ks}$.

other hand, a single stage martensitic transformation is recognized in the specimen B-A as shown in Fig. 5(b). The feature of DSC curve and transformation temperatures are almost the same as those in the specimen B-B in Fig. 3(b). These phenomena indicate that the controlling factor of the multistage martensitic transformation is the solution treat- (a)

(b)

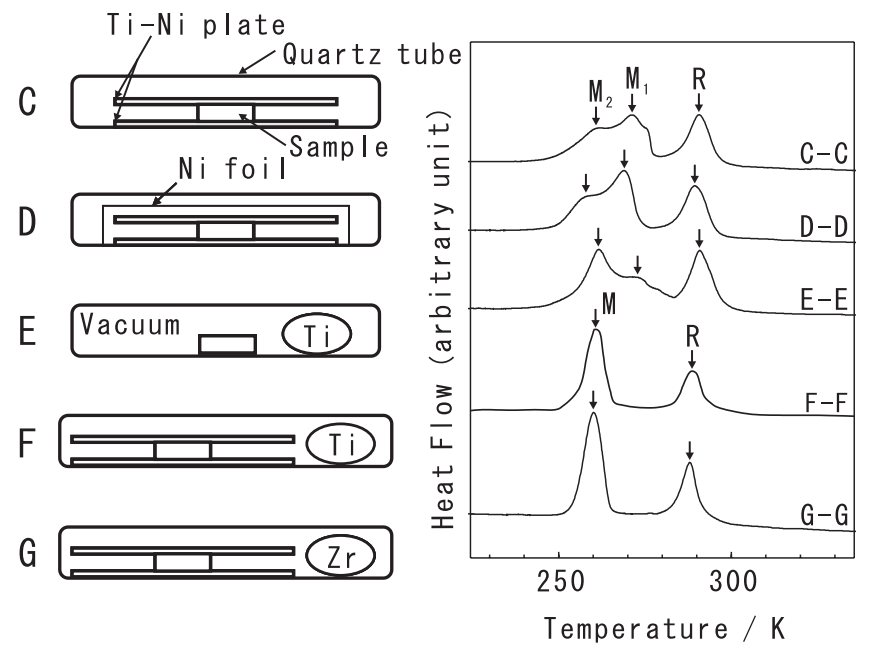

Fig. 6 (a) Schematic illustration of heat treatment conditions $\mathrm{C}$ to $\mathrm{G}$, and (b) corresponding DSC cooling curve of specimens C-C to G-G aged at $773 \mathrm{~K}$ for $7.2 \mathrm{ks}$.

ment condition. It is considered that a kind of compositional fluctuation is induced during the solution treatment with condition A and is emphasized during the aging treatment. Although the mechanism and process of compositional fluctuation during heat treatment have not been clarified yet, it may be related to the evaporation of $\mathrm{Ti}$ and $\mathrm{Ni}$, the preferential oxidation of Ti and so on. The precise analytical method is required to confirm this hypothesis. It is now under study and will be reported in due course.

In order to establish the further evidence experimentally, the specimens were heat treated under various conditions as illustrated in Fig. 6. The specimen is simply sandwiched between $\mathrm{Ti}-\mathrm{Ni}$ sheets with the same composition in an evacuated quartz tube, which is referred to as the condition $\mathrm{C}$. The condition D indicates that the specimen is sandwiched between Ti-Ni sheets with the same composition and then wrapped with $\mathrm{Ni}$ foil in an evacuated quartz tube. The specimen is evacuated with pure titanium block in the condition $\mathrm{E}$. The condition $\mathrm{F}$ indicates that the specimen is sandwiched between Ti-Ni sheets with the same composition and then evacuated with pure Ti block in a quartz tube. In the condition $\mathrm{G}$, the specimen is sandwiched between Ti-Ni sheets with the same composition and then evacuated with pure $\mathrm{Zr}$ block in a quartz tube. The specimens F-F and G-G aged at 773 for $7.2 \mathrm{ks}$ only show the single stage martensitic transformation and the rest show the multistage transformation. From these results one can imagine that the sandwiched Ti-Ni plates prevent the evaporation of $\mathrm{Ti}$ and $\mathrm{Ni}$ and/or the preferential oxidation of $\mathrm{Ti}$ in the specimen, and $\mathrm{Ti}$ and $\mathrm{Zr}$ blocks act as a getter material to purify the atmosphere in the evacuated quartz tube. It can be concluded that the multistage martensitic transformation is suppressible with the prevention of evaporation of $\mathrm{Ti}$ and $\mathrm{Ni}$ and/or preferential oxidation of $\mathrm{Ti}$ in the specimen, and the purification of atmosphere in the evacuated quartz tube. Both factors for the regulation of atmosphere are indispensable for suppressing the multistage martensitic transformation. 
(a) A

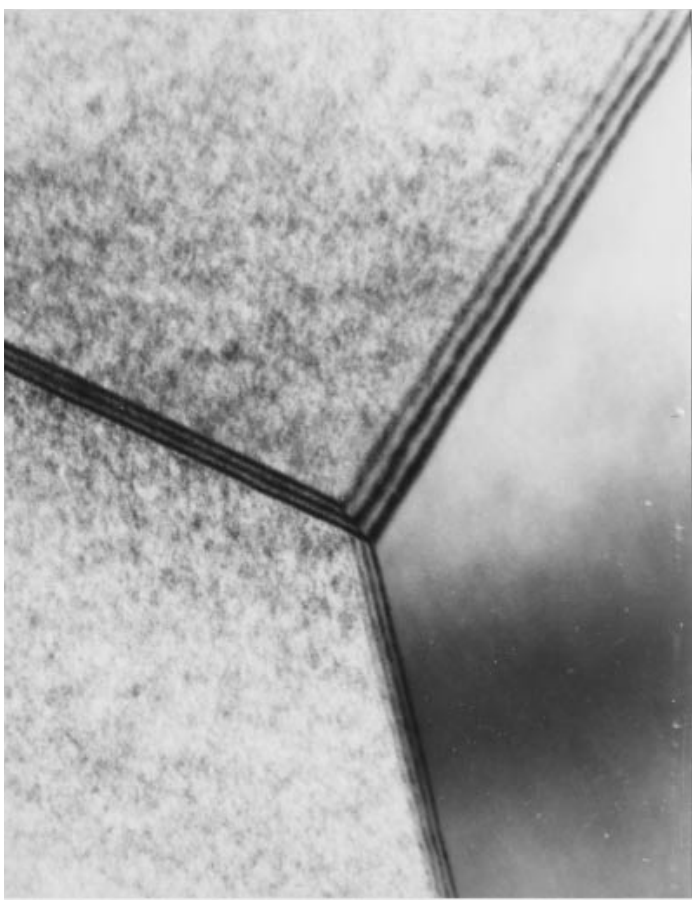

(b) B

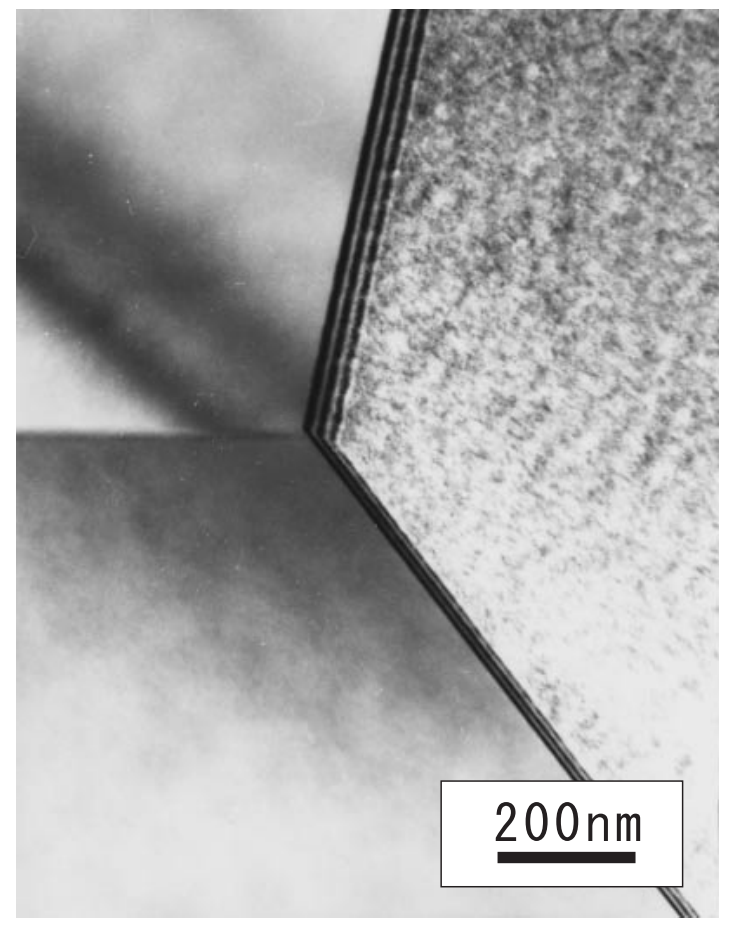

Fig. 7 Bright field image of solution treated specimen with the conditions (a) A and (b) B.

\subsection{Precipitation morphology of $\mathrm{Ti}_{3} \mathrm{Ni}_{4}$}

In order to obtain the microstructural aspects of each specimen, TEM observations were carried out. Figures 7(a) and (b) show the bright field image of solution treated specimen with the conditions A and B, respectively. No difference between the two images can be recognized on the conventional TEM scale. The average grain size of both the specimens is estimated to be about $40 \mu \mathrm{m}$. Figures 8(a) and (b) show the microstructure, respectively, at grain boundary and interior of the same grain in specimen A-A aged at $773 \mathrm{~K}$ for $3.6 \mathrm{ks}$. The size of $\mathrm{Ti}_{3} \mathrm{Ni}_{4}$ precipitate at the grain interior about $20 \mu \mathrm{m}$ away from boundary is about ten times larger than that at the grain boundary, while the precipitation density at the interior is lower than that at the boundary. The correspondence between $\mathrm{M}_{1}, \mathrm{M}_{2}$ and those transformation areas such as grain boundary or interior has not been clarified yet. However, since the martensitic phase has been occasionally observed at grain boundary after jet polishing around $270 \mathrm{~K}$, the transformation area of $\mathrm{M}_{1}$ and $\mathrm{M}_{2}$ may correspond to the grain boundary and interior, respectively. On the other hand, homogeneity in distribution and size of precipitates is observed at grain boundary and interior of the same grain in specimen B-B aged at $773 \mathrm{~K}$ for $3.6 \mathrm{ks}$ as shown in Figs. 8(c) and (d), respectively. It is recognized that $\mathrm{Ti}_{3} \mathrm{Ni}_{4}$ precipitate has the tendency of homogeneous nucleation in TiNi B2 matrix. It is due to similarity of atomic arrangement between TiNi $\mathrm{B} 2$ and $\mathrm{Ti}_{3} \mathrm{Ni}_{4}$ rhombohedral phases as mentioned above. ${ }^{19,20)}$ Although we do not reproduce electron micrographs in A-B, B-A, C-C, D-D, E-E, F-F and G-G specimens aged at $773 \mathrm{~K}$ for $3.6 \mathrm{ks}$ here, the microstructure in the specimen A-B is essentially similar to that in the specimen A-A. The microstructure in B-A, F-F and G-G is similar to that in the specimen B-B. In the rest specimens heterogeneous grain boundary precipitation and homogeneous one were randomly observed. Further details will be reported in due course together with the correspondence between $\mathrm{M}_{1}, \mathrm{M}_{2}$ and those transformation areas as mentioned above. These results demonstrate that the precipitate morphology is drastically changed with heat treatment atmosphere, especially with solution treatment condition. Consequently, the appearance of multistage martensitic transformation associated with heterogeneous precipitation of $\mathrm{Ti}_{3} \mathrm{Ni}_{4}$ is controlled with heat treatment atmosphere. We can finally conclude that the multistage martensitic transformation in aged Ni-rich Ti-Ni alloys is an extrinsic nature, i.e., a kind of artifact during the heat treatment.

In the present study we only investigate the aging of fully annealed, defect free materials. The multistage martensitic transformation has been also observed in the aged specimen after deformation. ${ }^{8,10,11)}$ Since it is likely that the solution treatment atmosphere prior to deformation was not carefully regulated in the previous works, ${ }^{8,10,11)}$ it should be reinvestigated with respect to the heat treatment atmosphere. However, it is difficult to regulate the heat treatment atmosphere from the industrial point of view. Therefore, further understanding of the multistage martensitic transformation mechanism is also required, although the transformation is an extrinsic nature, i.e., a kind of artifact during the heat treatment. Experimentally unsolved questions derived from the present study are listed as follows. The compositional fluctuation between grain boundary and interior upon solution treatment under normal atmosphere such as the condition A-A should be estimated with aid of analytical TEM, Auger electron spectroscopy and so on. Then the heterogeneous nucleation and growth mechanism of $\mathrm{Ti}_{3} \mathrm{Ni}_{4}$ phase should be discussed on the basis of compositional 
(a) A-A G. B.

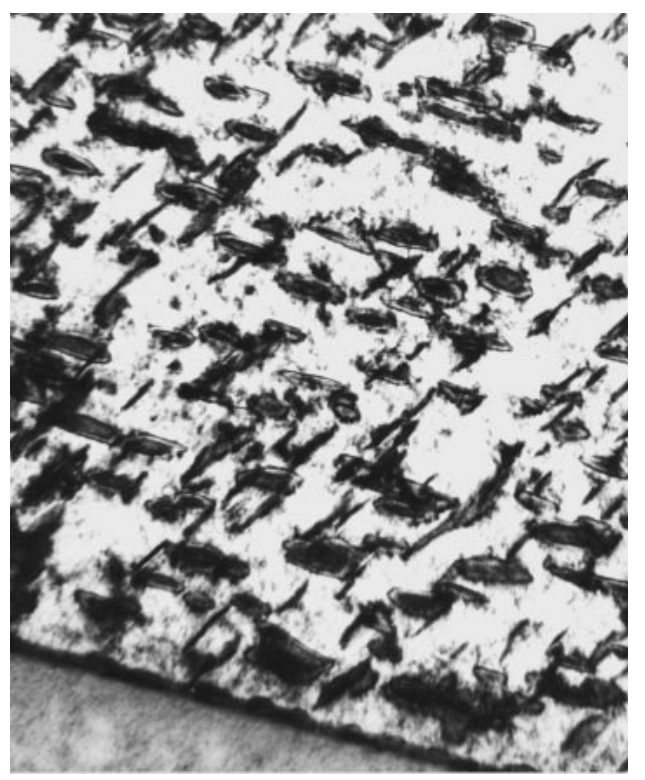

(c) B-B G. B.

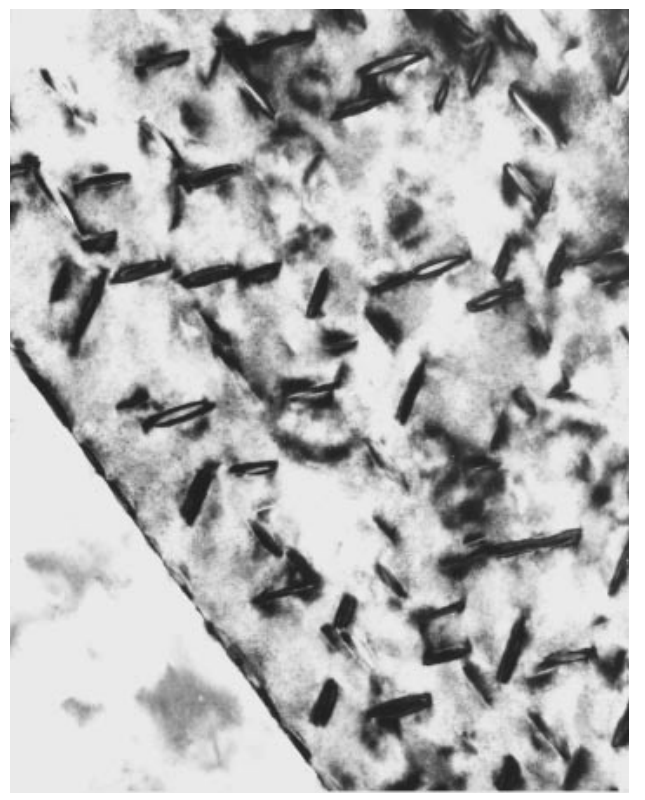

(b) A-A G. I.

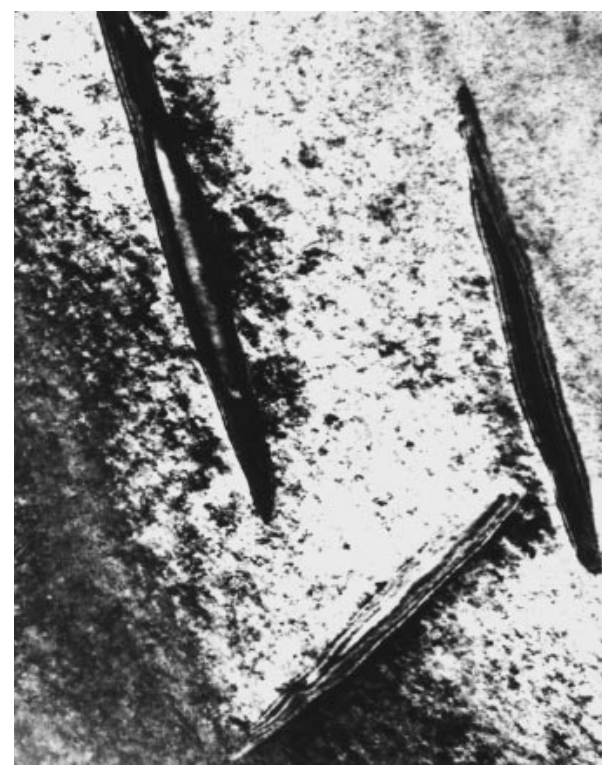

(d) B-B G. I.

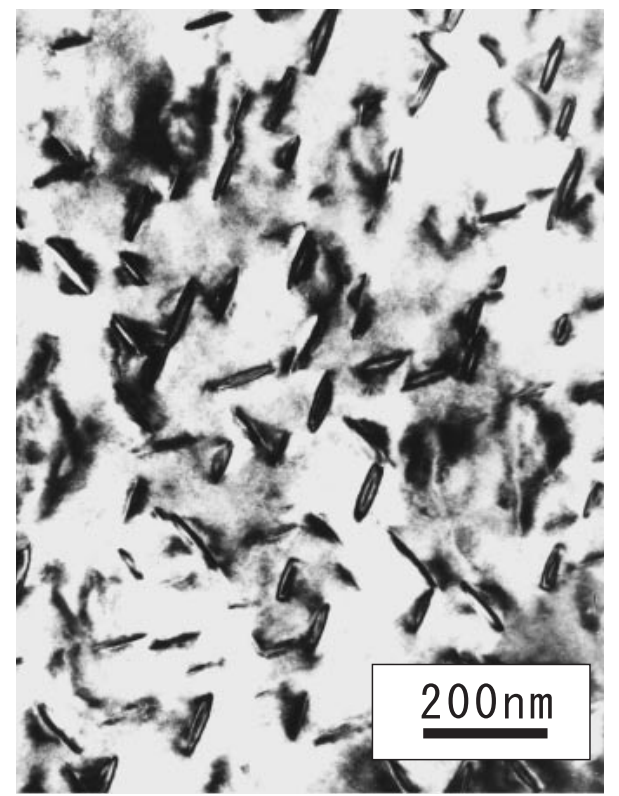

Fig. 8 Bright field images at grain boundary (G.B.) and interior (G. I.) of the same grain in specimens (a) and (b) A-A, and (c) and (d) B-B, aged at $773 \mathrm{~K}$ for $3.6 \mathrm{ks}$.

fluctuation result. The correspondence between $\mathrm{M}_{1}, \mathrm{M}_{2}$ and those transformation areas should be identified with metallographic techniques.

\section{Concluding Remarks}

In the present study we demonstrate that the appearance and disappearance of multistage martensitic transformation in aged Ni-rich Ti-Ni alloys depend on the heat treatment atmosphere. No multistage transformation occurs when the evaporation of $\mathrm{Ti}$ and $\mathrm{Ni}$ and/or the preferential oxidation of $\mathrm{Ti}$ in the specimen are prevented and the purification of heat treatment atmosphere is achieved. The heterogeneity in precipitation morphology of $\mathrm{Ti}_{3} \mathrm{Ni}_{4}$ phase, which is respon- sible for the multistage transformation, can be suppressed with the regulation of heat treatment atmosphere as mentioned above. We conclude that the multistage martensitic transformation is an extrinsic nature, i.e., a kind of artifact during the heat treatment, in aged Ni-rich Ti-Ni alloys.

\section{REFERENCES}

1) S. Miyazaki, Y. Ohmi, K. Otsuka and Y. Suzuki: J. Phys. 43 (1982) 255-260.

2) T. Saburi, T. Tatsumi and S. Nenno: J. Phys. 43 (1982) 261-266.

3) M. Nishida and T. Honma: Scr. Metall. 18 (1984) 1293-1298.

4) M. Nishida and T. Honma: Scr. Metall. 18 (1984) 1299-1301.

5) T. Todoroki and H. Tamura: Trans. JIM 28 (1987) 83-94.

6) J. S. Zhu and R. Gotthardt: Phys. Lett. A 132 (1988) 279-282. 
7) D. Stroz, J. Kwarciak and H. Morawiec: J. Mater. Sci. 23 (1988) 4127 4131 .

8) D. Favier, Y. Liu and P. G. McComick: Scr. Metall. Mater. 28 (1993) 669-672.

9) P. G. McCormick, Y. Liu, X. Chen and D. Favier: Trans. Mat. Res. Soc. Jpn. 18B (1994) 1105-1108.

10) L. Bataillard and R. Gotthardt: J. Phys. IV C8 (1995) 647-652.

11) H. Morawiec, D. Stroz, T. Goryczka and D. Chrobak: Scr. Mater. 35 (1996) 485-490.

12) L. Bataillard, J.-E. Bidaux and R. Gotthardt: Philos. Mag. A 78 (1998) 327-344.

13) J. Khalil-Allafi, X. Ren and G. Eggeler: Acta Mater. 50 (2002) 793-803.

14) J. Khalil-Allafi, A. Dlouhy and G. Eggeler: Acta Mater. 50 (2002) 4255-4274

15) Y. Nishida, J. I. Kim and S. Miyazaki: Collected Abstracts of the 2002
Fall Meeting of Japan Inst. Metals, p. 410

16) T. Hara, T. Ohba and K. Otsuka: Collected Abstracts of the 1997 Fall Meeting of Japan Inst. Metals, p. 365.

17) M. Nishida, C. M. Wayman and T. Honma: Scr. Metall. 18 (1984) 1389-1394.

18) M. Nishida, C. M. Wayman and T. Honma: Metall. Trans. 17A (1986) 1505-1515.

19) T. Tadaki, Y. Nakata, K. Shimizu and K. Otsuka: Trans. JIM 27 (1986) 731-740.

20) T. Saburi, S. Nenno and T. Fukuda: J. Less-Common Met. 12 (1986) 157-166

21) M. Nishida, C. M. Wayman and T. Honma: Maters. Sci. Eng. 93 (1987) 191-203.

22) T. Tadaki, Y. Nakata and K. Shimizu: Trans. JIM 28 (1987) 883-890.

23) P. Filip and K. Mazanec: Scr. Mater. 45 (2001) 701-707. 